\title{
O caso Hope: sensualidade feminina na vida doméstica e na vida pública ${ }^{1}$
}

\author{
Lígia Campos de Cerqueira Lana
}

Resumo: No final de 2011, uma campanha publicitária de lingerie, protagonizada por Gisele Bündchen, tornou-se um acontecimento ao ser denunciada pelo governo por contribuir para a manutenção das desigualdades entre homens e mulheres. No enredo da propaganda, a modelo resolve seus problemas domésticos através da sensualidade. Este artigo analisa a estrutura do acontecimento gerado pela denúncia governamental com base em textos veiculados na mídia. O objetivo não é avaliar a campanha publicitária, mas identificar em diversos textos midiáticos a maneira como a sensualidade feminina foi observada na experiência pública. A análise mostra que a condenação da ação do governo se sobrepõe ao debate das questões que envolvem a legitimidade da participação das mulheres na vida pública. Apesar da constante exaltação cultural da sensualidade feminina no Brasil, o caso pouco mobilizou o tema.

Palavras-chave: mulher pública; sensualidade; acontecimento

Abstract: The case of Hope*: feminine sensuality in private and public life - In late 2011, a lingerie advertising campaign starring model Gisele Bündchen became an event after the government criticized it for contributing to maintain the inequalities between men and women. The advertisements promoted sensuality as a strategy for women to solve problems in their private lives. This article analyzes the structure of this event based on stories published in the mass media, aiming not to evaluate the aforementioned advertising campaign but to determine how feminine sensuality was perceived by the public. The analysis reveals that the government's criticism undermines the debate about issues regarding the legitimacy of women's participation in public life. Despite the constant cultural exaltation of feminine sensuality in Brazil, this case did not mobilize the theme to any appreciable degree.

* A Brazilian lingerie manufacturer

Keywords: public woman; sensuality; event

1 Texto apresentado no XXI Encontro da Associação Nacional dos Programas de Pós-Graduação em Comunicação em 2012. 
No final de setembro de 2011, uma campanha publicitária de roupas íntimas mobilizou a atenção pública para o debate sobre as questões femininas no Brasil. Na série de anúncios da marca Hope², com o slogan "você é brasileira, use seu charme", a modelo Gisele Bündchen protagoniza situações em que precisa informar notícias problemáticas ao seu parceiro, como gastos fora do orçamento no cartão de crédito. O conceito da campanha estabelece o bom proveito da sensualidade nesses momentos - quando se veste apenas com lingerie, Gisele Bündchen está mais apta para discutir problemas. Alguns dias depois das primeiras exibições da propaganda, a Secretaria de Políticas para as Mulheres, órgão vinculado à Presidência da República, apresentou ao Conselho Nacional de Autorregulamentação Publicitária (Conar) uma representação contra as peças publicitárias.

A campanha poderia ter sido apenas mais uma das aparições de Gisele Bündchen na mídia. A mobilização diante de uma publicidade sexista protagonizada por Bündchen poderia também ter acontecido antes, no início de 2011, quando ela desempenhou o papel da dona de casa aprisionada à vida doméstica na propaganda da Sky. Entretanto, no caso Hope, Gisele Bündchen personificou uma controvérsia: ao encarnar o estereótipo da mulher sensual, ela estaria contribuindo para a desigualdade de gêneros? Durante três semanas, surgiram posicionamentos a respeito do acontecimento; especialistas, políticos, jornalistas e pessoas comuns criticaram e/ou apoiaram a campanha publicitária. Em 13 de outubro, o caso teve seu desfecho com o arquivamento da denúncia. Apesar da possibilidade de recorrer da decisão, a Secretaria de Políticas para as Mulheres não questionou o julgamento.

A campanha da Hope estabeleceu uma ruptura com a normalidade do cotidiano. $\mathrm{Na}$ medida em que rompe com o comum, o caso "pede" para ser compreendido, conforme Louis Quéré (2005). A análise do caso Hope deve lembrar que a participação das mulheres como personagens legítimas da vida pública - em ocupações diversas, de atrizes a ministras - começou a se tornar possível há pouco mais de um século. O caso Hope como situação concreta de avaliação da conduta feminina é parte de um contexto em que mulheres passam a ter a possibilidade de encarnar suas experiências na vida pública. No acontecimento, as mulheres são protagonistas das ocorrências: Gisele Bündchen é a modelo da propaganda; outras mulheres, representadas pela ministra Iriny Lopes, são as denunciantes; Nelcina Tropardi é a advogada-relatora do Conar.

Refletindo sobre as "mulheres públicas", Michelle Perrot (1998, p. 10) aponta que a atuação feminina em público torna-se mais frequente durante o século XIX, pois até aquele momento estava reservado "para os homens, o público e o político, seu santuário. Para as mulheres, o privado e seu coração, a casa". Apenas as prostitutas participavam livremente da vida pública por exercerem seu trabalho fora do âmbito doméstico. A situação começa

2 A Hope é uma marca de roupas íntimas fundada em 1966 em São Paulo por Nissim Hara. Segundo o site da marca, nos anos 2000, a empresa passou por um processo de "rejuvenescimento [...] foi da nova geração a ideia de colocar 'musas' para cada coleção. Já passaram pelo posto Ellen Jabour, Daniella Cicarelli, Juliana Paes e mais recentemente a top Gisele Bündchen". 
a se modificar com a circulação recorrente de mulheres em lojas, nos salões de chá e na lavanderia. Já nos primeiros momentos, as mulheres enfrentam dificuldades para transitar em público. Como critica Virginia Woolf (1985, p. 63), as escritoras do século XIX, por exemplo, negam o reconhecimento público: George Eliot (Mary Ann Evans) e George Sand (Amantine Lucile Aurore Dupin) "buscaram inutilmente esconder-se atrás de nomes masculinos", resistindo às homenagens públicas, pois "a glória da mulher é não ser falada".

A gradual ocupação dos espaços públicos ampliou a igualdade entre homens e mulheres desde o século XIX. Apesar dos avanços, o caso Hope realça o caráter agonístico da inserção feminina em público. A propaganda traz para o espaço midiático valores relacionados à vida íntima que, sob o ponto de vista do acontecimento, têm menos importância que a sua natureza pública. A narrativa encarnada no corpo de uma mulher excepcionalmente bem-sucedida torna público o uso estratégico da sensualidade. Dessa maneira, quando ensina que a sensualidade é a maneira correta de resolver problemas, a campanha da Hope retoma o passado. "Selvagem, instintiva, mais sensível que racional, ela incomoda e ameaça. A mulher noturna, mais ou menos feiticeira, desencadeia as forças irreprimíveis do desejo. [...] O corpo das mulheres, seu sexo, esse poço sem fundo, apavora." (PERROT, 1998, p.8). Excluídas da experiência pública, aquelas que insistiam em estar fora do âmbito doméstico, geralmente as prostitutas, representavam as mulheres perigosas, que colocavam em risco a vida coletiva. Na campanha da Hope, o corpo da mulher ainda simboliza sua arma; os homens permanecem ameaçados pelo feminino.

A mulher contemporânea exerce outras ocupações além do trabalho de prostituta, no entanto, o caso Hope mostra que os valores do feminino ainda carregam marcas do extenso histórico de exclusão da vida pública. Sandra Azeredo (2007) levanta um problema curioso: até o século XX, "mulher pública" figura no dicionário Aurélio como prostituta; atualmente, não existe mais nenhuma definição do termo. "No Dicionário Novo Aurélio - século XXI só existe a definição 'homem público' no verbete 'homem' ('indivíduo que se consagra à vida pública, ou que a ela está ligado'). Não existe 'mulher pública'" (AZEREDO, 2007, p. 27).

Essa ausência do verbete sugere que as desigualdades de condições na vida pública adquirem novos valores. Até o século XIX, os limites para a participação na vida pública eram nítidos. Denunciar ou aprovar a campanha Hope incide em valores semelhantes: impedindo que uma mulher exiba seu corpo em público, retornamos ao aprisionamento doméstico; aceitando a presença da sensualidade traiçoeira, estamos também voltando ao passado, em que a mulher representa uma ameaça por provocar desejo.

Esse tipo de impasse não é novidade para os estudos feministas da mídia. Angela McRobbie (2004), discutindo a perda da força do feminismo a partir dos anos 1990, retoma a propaganda de sutiãs Wonderbra. Na imagem, Eva Herzigova admira seus seios, jogando com o olhar do desejo e "indicando o feminismo como coisa do passado 
ao provocativamente 'decretar o sexismo'"13 (MCROBBIE, 2004, p. 259). A propaganda mobilizou na época a compreensão sobre o politicamente correto, o que gerou reações contra um "feminismo puritano". Quando opinavam sobre o anúncio, as mulheres comuns demonstravam conhecer o ponto de vista do feminismo, mas defendiam a propaganda baseadas na ideia de liberdade de escolha.

O debate sobre o anúncio de 1995 permanece ainda atual. Na campanha da Hope, há elementos semelhantes ao caso Wonderbra: a sensualidade, o desejo e o humor. A ideia da liberdade de escolha aparece como estratégia individual da mulher para enganar o homem em casa. Apesar das analogias, não é possível chegar a uma avaliação conclusiva a respeito da situação da exposição pública do corpo. Como estratégia individualizante, o uso da sensualidade na propaganda da Hope deve ser criticado; ao mesmo tempo, é preciso considerar se não haveria um retrocesso na censura ao corpo feminino em público. Para compreender o caso Hope, a participação das mulheres como personagens legítimas da experiência pública - com corpos que podem circular livremente - deve ser problematizada.

A argelina Wassyla Tamzali (2009), duramente crítica ao relativismo cultural das feministas ocidentais, apresentou recentemente um argumento esclarecedor para essa questão. Discutindo o uso do véu pelas mulheres islâmicas, Tamzali mostra que o sentido religioso para a manutenção do costume perpetua a submissão feminina, pois, quando usam o véu, as mulheres são impedidas de ocupar o espaço público de maneira igualitária. As conquistas do feminismo referem-se à participação no espaço público, o que deveria, por consequência, resultar em críticas ao uso do véu. Ao contrário, muitas ocidentais, ao se posicionarem favoravelmente ao véu (embasadas em uma perspectiva de respeito à diversidade cultural), desconsideram que as muçulmanas, com corpos cobertos, estão impedidas de participar integralmente da vida pública.

Em árabe argelino, para dizer que uma mulher não usa o véu, dizemos que ela está nua. Os islâmicos, com cinismo, retomam essa expressão e dizem que o uso do véu é uma escolha e que uma mulher é livre para estar ou não nua. [...] Trata-se de uma obrigação forçada pela violência do ambiente social, dominado por uma visão teologizada da sexualidade. É essa violência que é recebida como a marca da diversidade do mundo nas capitais europeias ${ }^{4}$ (TAMZALI, 2009, p. 108-109).

A obrigatoriedade de cobrir o corpo compõe o quadro da violência contra as muçulmanas. Tamzali se diz "em cólera" ${ }^{5}$ com as europeias "desabusadas" que colocam

3 "taking feminism into account by showing it to be a thing of the past, by provocatively 'enacting sexism'" (tradução nossa).

4 "En arabe algérien, pour dire qu'une femme ne porte pas le voile, on dit qu'elle est nue. Les islamistes, avec cynisme, reprennent cette expression et disent que le port du voile est un choix et qu' une femme est libre d'être nue ou pas. [...] Il s'agit d'une mise au pas forcée par la violence de l'environnement social, dominé par une vision théologisée de la sexualité. C'est cette violence qui est reçue comme la marque de la diversité du monde dans les capitales européennes" (tradução nossa).

5 Joumana Haddad (2011) aponta também um sentimento de "fúria" no subtítulo de Eu matei Sherazade. 
em segundo plano um dos aspectos fundamentais para a igualdade de gêneros - a equidade na experiência pública.

No Brasil, não se determina esconder o corpo feminino, no entanto, em muitos aspectos, a condição das mulheres no espaço público assemelha-se ao contexto muçulmano. Lá, a violência cultural leva à ocultação do corpo; aqui, a exaltação da sensualidade ensina que as mulheres devem ser sedutoras em público. A mulher-objeto das propagandas de cerveja, as mulheres-fruta e a bonita apresentadora de televisão que se autodenomina "burra" são alguns exemplos. Além disso, a violência cultural brasileira implica que mulheres, mesmo não exercendo uma profissão relacionada ao corpo, precisem despertar o charme. Isso amplifica o que Erving Goffman (2009) denomina "o arranjo entre os sexos", em que a mulher deve cuidar e ser amável, o contrário da postura usual no trabalho, de frieza e objetividade.

O caso Hope é importante para o debate brasileiro, pois demanda que valores ligados à conduta da mulher sejam debatidos com base na sensualidade. Motivados pela astúcia sexual feminina, o enredo das peças publicitárias e a denúncia do governo colocam em perspectiva os sentidos atribuídos à expressão do corpo feminino.

\section{A campanha publicitária}

Antes de passar à análise do acontecimento, a descrição dos filmes da campanha "Hope ensina" estabelece com mais precisão os elementos que levam à denúncia do governo. Desenvolvidos pela agência Giovanni+DraftFCB, os filmes têm uma estrutura narrativa organizada em dois momentos: o primeiro errado, o segundo certo. No momento errado, Gisele Bündchen aparece em pé, vestida com roupas comuns, em plano americano com fundo branco, anunciando um suposto problema para seu companheiro, olhando diretamente para a câmera. Depois da fala, uma inserção gráfica ao lado da tela, acompanhada de uma vinheta sonora, indica "errado". Em seguida, as luzes se apagam e Gisele Bündchen aparece vestida com roupas íntimas, em plano aberto que mostra seu corpo inteiro, anunciando para a câmera o mesmo problema. Quando termina de falar, a inserção gráfica indica "certo". Como epílogo, a voz masculina em off conclui: "você é brasileira, use seu charme", enquanto Gisele Bündchen desfila do lado esquerdo para o lado direito da tela, em um cenário branco com o fundo escrito "HOPE: bonita por natureza".

No filme "Mãe vem para cá", Gisele Bündchen usa um vestido bege-escuro na primeira parte. Com os braços esticados e cruzando as mãos para frente, ela anuncia, sem graça, "amor, a mamãe vem morar com a gente". O letreiro "errado" aparece em cores amarelas. Em seguida, ela aparece vestida com calcinha e sutiã amarelos, dizendo o mesmo conteúdo, agora com uma expressão mais sorridente em um plano aberto que mostra seu corpo inteiro. O aviso "certo" surge ao lado da tela. Em seguida, a câmera se aproxima em um plano americano e ela completa "não é o máximo?". 
Em "Estourei o cartão", Gisele Bündchen, vestida com regata cor-de-rosa e bermuda bege, anuncia constrangida: "amor, sabe seu cartão de crédito? Puff..." . O letreiro "errado" surge em azul. Em seguida, vestida com roupas íntimas azuis, ela fala com uma das mãos na cintura e movendo o quadril para o lado: "amor, eu estourei o limite do cartão de crédito". A câmera se aproxima, e ela finaliza: "do seu e do meu".

No filme "Bati o carro", a modelo usa um vestido branco e, mexendo nos cabelos, avisa "amor, eu bati seu carro". O letreiro "errado" aparece com a cor vermelha. Em seguida, com calcinha e sutiã vermelhos, ela põe as duas mãos na cintura e fala: "amor, eu preciso te falar uma coisa, eu bati seu carro". A câmera faz um enquadramento mais próximo, e ela completa: "de novo...".

\section{A estrutura do acontecimento ${ }^{6}$}

A campanha da Hope é lançada em 20 de setembro de 2011. Neste momento, as revistas de marketing anunciam os bastidores da produção. Na revista Meio \& Mensagem, a campanha é descrita como "uma aula de sedução" dada por Gisele Bündchen, que associa "o poder da sedução à assinatura: você é brasileira, use seu charme". Gisele Bündchen foi quem indicou a agência Giovanni+DraftFCB para a marca Hope. "A top model conhece bem o trabalho da agência, responsável pelos filmes da Sky que protagoniza. Gisele considerou que a operadora de TV por assinatura via satélite foi um dos anunciantes que melhor usou a sua imagem" (GISELE..., 2011a). Na Exame, a campanha é anunciada como o "ensinamento" para deixar qualquer homem "derretido" (GISELE..., 2011b). Até esse momento, existe um evento corriqueiro relacionado à publicidade: como no lançamento de qualquer campanha, as publicações especializadas anunciam as peças da Hope.

Em 26 de setembro, a Secretaria de Políticas para as Mulheres apresenta a representação ao Conar. O documento de cinco páginas requer "a imediata sustação da publicação da propaganda". Os "fatos e fundamentos" apontados para a representação são: reforço do estereótipo "equivocado da mulher como mero objeto sexual de seu marido", "conteúdo discriminatório contra a mulher", padrões culturais que "mantêm formas de dominação" e "desrespeito à capacidade intelectual e criativa das mulheres" (SECRETARIA..., 2011). O acontecimento tem início com a denúncia. Tendo em vista os principais eventos que compõem o caso, quatro datas organizam as ocorrências nos textos coletados na mídia.

6 O corpus foi delimitado em jornais e revistas de circulação nacional (O Globo, Folha de S.Paulo, O Estado de S. Paulo, Veja, Época, Istoé e Carta Capital) e na televisão aberta (Globo, SBT, Rede TV!, Band e Record). O procedimento de coleta utilizou as ferramentas de busca dos sites das publicações, com os filtros temporais do acontecimento associados a duas palavras-chave "Hope" e "Gisele Bündchen". No caso da televisão, a busca foi feita também no Youtube. 


\begin{tabular}{|c|c|c|c|c|}
\hline Data & $\mathbf{2 0}$ set. & $\mathbf{2 6}$ set. & $\mathbf{1}$ out. & $\mathbf{1 3}$ out. \\
\hline Fase & $\begin{array}{c}\text { O } \\
\text { acontecimento } \\
\text { ainda não } \\
\text { surgiu }\end{array}$ & $\begin{array}{c}\text { 1a fase: o } \\
\text { surgimento do } \\
\text { acontecimento }\end{array}$ & $\begin{array}{c}\text { 2a fase: a } \\
\text { exposição dos } \\
\text { posicionamentos }\end{array}$ & $\begin{array}{c}\text { 3a fase: o } \\
\text { julgamento } \\
\text { do Conar }\end{array}$ \\
\hline $\begin{array}{c}\text { Ocorrência } \\
\text { principal }\end{array}$ & $\begin{array}{c}\text { Lançamento de } \\
\text { uma campanha } \\
\text { publicitária }\end{array}$ & $\begin{array}{c}\text { Denúncia do } \\
\text { governo }\end{array}$ & $\begin{array}{c}\text { Divulgação } \\
\text { dos sentidos do } \\
\text { acontecimento }\end{array}$ & $\begin{array}{c}\text { Anúncio do } \\
\text { fim do acon- } \\
\text { tecimento }\end{array}$ \\
\hline
\end{tabular}

Tab. 1. Evolução temporal do acontecimento Fonte. Dados da pesquisa.

Depois que o acontecimento surge, três fases de ocorrências foram identificadas. A primeira refere-se ao momento imediatamente posterior à representação do governo, em que a mídia contextualiza os motivos para o pedido de suspensão. Em 29 de setembro, O Globo traz uma matéria que cita trechos do documento. "A propaganda promove o reforço do estereótipo equivocado da mulher como objeto sexual de seu marido e ignora os grandes avanços que temos alcançado para desconstruir práticas e pensamentos sexistas', diz a nota publicada no site da secretaria." O jornal também apresenta o lado da Hope, que "recorreu à Gisele Bündchen, mulher bem-sucedida internacionalmente, 'para evitar que fôssemos analisados sob o viés da subserviência ou dependência financeira da mulher'" (SEABRA, 2011). A Folha de S.Paulo explica como ocorre o processo de julgamento pelo Conar. "Caso entenda que a campanha fere, de fato, o código do setor, o Conar pode recomendar a suspensão definitiva do comercial. A esse tipo de decisão, cabe recurso" (GUERLENDA; NUBLAT, 2011). Nesse momento, a revista Veja também não informa seu ponto de vista sobre o caso, publicando apenas uma notícia sintética sobre a denúncia (GOVERNO..., 2011).

O Bom Dia Brasil anuncia a abertura de investigação pelo Conar, afirmando que "o comercial foi considerado preconceituoso por algumas mulheres" (CONAR..., 2011a). O telejornal Rede TV! News, apesar de não divulgar uma opinião sobre o caso, conclui que "politicamente incorreto ou não, o fato é que a marca caiu na boca do povo" (COMERCIAL..., 2011).

Na primeira fase de ocorrências, apenas a revista Carta Capital torna público seu posicionamento. Em três textos publicados entre os dias 27 e 29 de setembro, a revista apoia o pedido de suspensão da propaganda, trocando o nome de Gisele por Amélia Bündchen.? A primeira matéria condena a campanha pelos estereótipos que promove, como de "sedutora inveterada". "Vale lembrar do recente caso com brasileiras na Europa,

7 Apenas em um texto da Carta Capital, assinado por Nirlando Beirão e republicado no site da revista em 29 de setembro, existe o ponto de vista contrário à representação do governo. 
que sofrem com preconceito associado à imagem da prostituição e do charme do corpo" (ROMAN, 2011). No segundo texto, a revista contextualiza a denúncia e informa a posição da Hope: "no site da empresa, o recado da top segue firme e forte em seu vídeo promocional: 'você é brasileira, use seu charme'. Recado dado, Amélia" (PICHONELLI, 2011). No terceiro texto, a revista chama atenção para as desigualdades entre homens e mulheres no mercado de trabalho.

\begin{abstract}
A propaganda faz a mulher voltar no tempo. Devolve a emancipada Gisele ao lar que sua avó habitou um dia. A divisão sexual do trabalho e as desigualdades de gênero ainda presentes no imaginário social são os principais limitadores da equidade de gênero no mercado de trabalho (CASTRO, 2011).
\end{abstract}

Nos dias que se seguem, a mídia passa a publicar suas avaliações sobre o caso, o que marca a segunda fase de ocorrências do acontecimento, iniciada aproximadamente em 1 ㅇ de outubro. Em O Globo, a coluna de humor ridiculariza a representação do governo, afirmando que "a Gisele Bündchen, exibindo aquele corpaço desnudo e com tudo de fora, deixa qualquer criatura do sexo feminino humilhada"(AGAMENON, 2011). Na Folha de S.Paulo, dois artigos assinados criticam a campanha da Hope, mas não defendem a representação do governo. Gilberto Dimenstein (2011) acredita que "o governo entrar como entrou contra o comercial soa um tanto ridículo", sendo o problema da campanha "a sensação de que o politicamente correto é ser chato e intolerante. Quando, na verdade, o que se combate é a intolerância em nome do respeito à diversidade". Da mesma maneira, João Pereira Coutinho (2011) desaprova a propaganda sem apoiar o governo, já que, para ele, "o verdadeiro insulto é aos homens. A lingerie Hope, ao apresentar Gisele de calcinha e sutiã para comunicar o estouro do cartão de crédito, está simplesmente a dizer: os homens são tão básicos e imbecis que basta você aparecer em lingerie para eles perdoarem tudo".

O Estado de S. Paulo se posiciona de maneira favorável à campanha publicitária. No texto de Sérgio Augusto (2011), a justificativa para isso "deriva justamente do contraste entre a personagem e sua intérprete, do absurdo das situações neles exploradas [...] ainda não nasceu o homem capaz de reduzir Gisele à condição de teúda e manteúda".

A revista Veja critica o "moralismo oficial" da denúncia por ser a "mais recente manifestação do desejo do governo assumir o papel de bedel da sociedade, ditando o que é certo e errado" (VARGAS, 2011). Na Época, Paulo Moreira Leite (2011) não explicita sua opinião sobre a campanha, mas assinala que a denúncia não se constitui como censura, já que "a decisão não será resolvida pelo governo. Tem a ver com uma instituição privada. Os próprios publicitários escolhem os dirigentes e resolvem o que fazer nestes casos".

A fase final de ocorrências refere-se aos momentos posteriores ao anúncio do parecer do Conar em 13 de outubro. A Folha de S.Paulo anuncia que o "Conar libera propaganda da Hope com Gisele Bündchen" de forma unânime em sessão de julgamento acompanhada por "representantes do governo, do anunciante e da agência" (CONAR..., 2011d). 
O governo "não vai recorrer contra a decisão do Conar. [...] Para a secretaria, apenas por ter aceitado que o comercial fosse a julgamento, o conselho admitiu a importância do debate" (GUERLENDA, 2011).

O Estado de S. Paulo apresenta o argumento da decisão. "Os membros presentes à sessão do julgamento acompanharam o voto do relator do caso, que considerou que os estereótipos utilizados nas propagandas 'são comuns à sociedade e facilmente identificados por ela, não desmerecendo a condição feminina'” (PIRES, 2011). A mesma matéria é republicada em Veja e Istoé.

A Carta Capital anuncia o julgamento do Conar sem críticas - não retomando seu posicionamento na primeira fase do caso. "O Conselho de Ética do Conselho Nacional de Autorregulamentação Publicitária (Conar) decidiu arquivar o pedido de suspensão da publicidade da Hope." A ministra responsável pela denúncia estaria "na berlinda" da reforma ministerial de 2012, já que "choveram críticas contra a ministra Iriny Lopes, acusada de censurar liberdade de expressão" (CONAR..., 2011b). A revista, assim, muda seu ponto de vista ao longo do evento. O Jornal da Globo também anuncia de maneira breve o desfecho do caso (CONAR..., 2011e). Em todos os textos coletados, apenas o SBT Brasil traz na etapa final críticas ao Conar.

Ainda são os homens que definem nosso papel principal: o de mulher-objeto para vender lingerie, cerveja, tanto faz. Mulher nem precisa falar, é só se expor, é triste. Mulheres-objeto estampam capas de revista, mas também mancham as páginas policiais. Enquanto não se valorizarem, jamais encontrarão seu verdadeiro poder, que nada tem a ver com o corpo, o sexo ou a sedução (CONAR..., 2011c).

\section{Apontamentos finais}

Quando emerge, o caso Hope prenuncia um debate importante para a compreensão das desigualdades entre homens e mulheres no Brasil. A denúncia pública contra a campanha publicitária, considerada discriminatória, suscitaria a compreensão de sentidos atribuídos atualmente ao corpo feminino. No entanto, a análise do acontecimento na mídia indica que não houve a incorporação da sensualidade feminina como um elemento na narrativa do caso. Os textos da mídia, ignorando a situação problemática trazida pelos filmes da Hope, estruturam-se na crítica ao governo. Nas publicações, fala-se em "estranheza", "moralismo" e governo como "bedel". Na Veja, o caso perde destaque para o contexto de outras ações do governo. Na Folha, a campanha é considerada tão errada como a denúncia, mas a condenação da publicidade menciona apenas a "diversidade" e o "insulto" aos homens. O Estado de S. Paulo é um dos poucos a problematizar a campanha, mas se restringe ao argumento da Hope: Bündchen nunca seria reduzida a "teúda" ou "manteúda". 
Os estudos feministas ressaltam que as maneiras como as mulheres aparecem na mídia estão relacionadas à legitimidade de sua participação na vida pública. Gisele Bündchen, mulher bem-sucedida, deu vida a uma personagem específica, encarnando na cena público-midiática uma suposta estratégia feminina na vida doméstica. O caso Hope poderia ter problematizado esse assunto, mas isso não ocorreu.

Dessa maneira, os aspectos que teriam motivado a denúncia pública permanecem incompreensíveis. A questão trazida pelo enredo da campanha publicitária não é debatida -seria correto a mulher usar seu corpo como estratégia na vida doméstica? Complementarmente, os textos também não indicam se seria aceitável mediatizar essa experiência privada no espaço público com o objetivo de vender roupas íntimas.

Um único texto traz os sentidos da sensualidade feminina na propaganda. Publicado pelo jornal $O$ Globo, o artigo de Agamenon restringe-se a criar uma atmosfera de disputa entre as mulheres, que estariam com inveja do "corpaço" de Gisele Bündchen.

A crítica ao governo possui mais relevância que o objeto da denúncia, que desaparece mesmo nos poucos textos que avaliam negativamente a campanha da Hope. Em geral, a mídia leva à conclusão de que houve um equívoco do ministério e, com o arquivamento da denúncia, a quase ausência de novos argumentos indica que a decisão do Conar coincide com o posicionamento adotado na narrativa (o caso se encerrou como era desejado). Sendo as verbas publicitárias responsáveis pela sustentação da mídia comercial massiva, é natural que não tenha existido desacordo com a deliberação de um dos órgãos mais representativos da publicidade no Brasil. Além disso, com os poucos posicionamentos reprováveis à campanha da Hope, o burburinho trazido pelo acontecimento pode ter sido mais positivo que negativo. Na disputada visibilidade midiática, a propaganda transbordou o horário comercial e alcançou outras seções da mídia, elevando os índices de audiência da marca.

A representação do governo, tão criticada, parece não ter proporcionado um bom começo ao acontecimento - e acabou por centralizar a atenção de toda a narrativa midiática. Ao analisar o texto da denúncia, nota-se que não existem argumentos consistentes para a compreensão do assunto. Quando menciona o estereótipo de "objeto sexual", não se relaciona a violência simbólica da propaganda ao papel feminino em público. Há somente a caracterização da mídia como "uma via expressa de propagação de padrões culturais", desconectada dos sentidos do ser mulher pública/ser sensual.

Apesar disso, o caso dialoga com os valores do processo mais amplo da expressão das mulheres em público. Por haver existido, ele abre pistas para os caminhos da busca pelo respeito entre mulheres e homens na experiência pública. 
Lígia Lana é bolsista de pós-doutorado júnior (CNPq) na Universidade Federal do Rio de Janeiro e doutora em Comunicação pela Universidade Federal de Minas Gerais com estágio sanduíche na École des Hautes Études en Sciences Sociales.

ligialana@gmail.com

\section{Referências}

AGAMENON. Hoje ainda é dia de rock! In: O Globo, Rio de Janeiro, 2 out. 2011. Disponível em: <http://oglobo.globo.com/cultura/agamenon/posts/2011/10/02/hoje-ainda-dia-de-rock-407473.asp>. Acesso em: 19 set. 2012.

AUGUSTO, Sérgio. Femininamente incorreta. In: O Estado de S. Paulo, São Paulo, 2 out. 2011. Disponível em: $<$ http://www.estadao.com.br/noticias/suplementos,femininamente-incorreta,780328,0. htm>. Acesso em:19 set. 2012.

AZEREDO, Sandra. Preconceito contra a "mulher": diferença, poema e corpos. São Paulo: Cortez, 2007.

CASTRO, Bárbara. Não é só propaganda. In: Carta Capital, São Paulo, 29 set. 2011. Disponível em: <http://www.cartacapital.com.br/politica/nao-e-so-uma-propaganda/>. Acesso em: 19 set. 2012.

COMERCIAL com Gisele Bündchen gera polêmica. Rede TV!, São Paulo, 29 set. 2011. Disponível em: <http://www.youtube.com/watch?v=i4z2qvuLH20>. Acesso em: 19 set. 2012.

CONAR analisa se suspende um comercial de lingerie com Gisele Bündchen. In: Rede Globo, Rio de Janeiro, 30 set. 2011. Disponível em: <http://globotv.globo.com/rede-globo/bom-dia-brasil/v/conar-analisase-suspende-um-comercial-de-lingerie-com-gisele-bundchen/1647038/>(a). Acesso em: 19 set. 2012.

CONAR arquiva pedido. In: Carta Capital, São Paulo, 13 out. 2011. Disponível em: <http://www. cartacapital.com.br/sociedade/conar-arquiva-pedido-de-suspensao-de-publicidade/> (b). Acesso em: 19 set. 2012.

CONAR libera comercial com Gisele Bündchen de lingerie. In: SBT, São Paulo, 13 out. 2011. Disponível em: <http://www.youtube.com/watch?v=0a8xvCui_EY>(c). Acesso em: 19 set. 2012.

CONAR libera propaganda da Hope com Gisele Bündchen. In: Folha de S.Paulo, São Paulo, 13 out. 2011. Disponível em: <http://www1.folha.uol.com.br/cotidiano/990055-conar-libera-propagandada-hope-com-gisele-bundchen.shtml>(d). Acesso em: 19 set. 2012.

CONAR recusa pedido de suspensão de comercial com Gisele Bundchen. In: Rede Globo, Rio de Janeiro, 13 out. 2011. Disponível em: <http://globotv.globo.com/rede-globo/jornal-da-globo/v/ conar-recusa-pedido-de-suspensao-de-comercial-com-gisele-bundchen/1662233/>(e). Acesso em: 19 set. 2012.

COUTINHO, João Pereira. O insulto de Gisele Bündchen. In: Folha de S.Paulo, São Paulo, 3 out. 2011. Disponível em: <http://www1.folha.uol.com.br/colunas/joaopereiracoutinho/984569-o-insultode-gisele-bundchen.shtml>. Acesso em: 19 set. 2012.

DIMENSTEIN, Gilberto. O pior do caso da Gisele Bündchen. In: Folha de S.Paulo, São Paulo, 30 set. 
2011. Disponível em: <http://www1.folha.uol.com.br/colunas/gilbertodimenstein/983419-o-pior-docaso-da-gisele-bundchen.shtml>. Acesso em: 19 set. 2012.

GISELE Bündchen dá aula de sedução. In: Meio \& Mensagem, São Paulo, 20 set. 2011. Disponível em: <http://meioemensagem.com.br/home/comunicacao/noticias/2011/09/20/Gisele-Bundchen-daaula-de-seducao.html>(a). Acesso em: 19 set. 2012.

GISELE Bündchen ilustra campanha da Hope. In: Exame, São Paulo, 20 set. 2011. Disponível em: <http://exame.abril.com.br/marketing/noticias/gisele-bundchen-ilustra-campanha-da-hope >(b). Acesso em: 19 set. 2012.

GOFFMAN, Erving. L'Arrangement entre des sexes. Paris: La Dispute, 2009.

GOVERNO pede ao Conar a suspensão da propaganda de lingerie com Gisele Bündchen. In: Veja, São Paulo, 28 set. 2011. Disponível em: <http://veja.abril.com.br/noticia/economia/governo-pedeao-conar-a-suspensao-da-propaganda-de-lingeire-com-gisele-bundchen>. Acesso em: 19 set. 2012.

GUERLENDA, Nádia; NUBLAT, Johanna. Conar abre processo para avaliar propaganda com Gisele Bündchen. In: Folha de S.Paulo, São Paulo, 29 set. 2011. Disponível em: <http://www1.folha.uol. com.br/cotidiano/983058-conar-abre-processo-para-avaliar-propaganda-com-gisele-bundchen. shtml>. Acesso em: 19 set. 2012.

GUERLENDA, Nádia. Governo diz que não vai recorrer contra comercial de Gisele Bündchen. In: Folha de S.Paulo, São Paulo, 13 out. 2011. Disponível em: <http://www1.folha.uol.com.br/ cotidiano/990177-governo-diz-que-nao-vai-recorrer-contra-comercial-de-gisele-bundchen.shtml>. Acesso em: 19 set. 2012.

HADDAD, Joumana. Eu matei Sherazade: confissões de uma árabe enfurecida. São Paulo: Record, 2011.

LEITE, Paulo Moreira. Rafinha, Gisele e a nossa liberdade. In: Época, São Paulo, 7 out. 2011. Disponível em: <http://colunas.revistaepoca.globo.com/paulomoreiraleite/2011/10/07/>. Acesso em: 19 set. 2012.

MCROBBIE, Angela. Post-Feminism and Popular Culture. In: Feminist Media Studies, vol. 4, n. 3. Londres: Taylor \& Francis, 2004, p. 255-264.

PERROT, Michelle. Mulheres públicas. São Paulo: Editora Unesp, 1998.

PICHONELLI, Matheus. Amélia Bündchen deixa mulheres em fúria. In: Carta Capital, São Paulo, 28 set. 2011. Disponível em: <http://www.cartacapital.com.br/sociedade/gisele-amelia-bundchenenfurece-as-feministas/>. Acesso em: 19 set. 2012.

PIRES, Fabiana. Conar libera campanha com Gisele Bündchen. In: O Estado de S. Paulo, São Paulo, 14 out. 2011. Disponível em: <http://www.estadao.com.br/noticias/impresso,conar-libera-campanhacom-gisele-bundchen,785206,0.htm>. Acesso em: 19 set. 2012.

SECRETARIA DE POLÍTICAS PARA AS MULHERES DA PRESIDÊNCIA DA REPÚBLICA. [Representação contra a propaganda da Hope lingerie]. Brasília, 26 set. 2011. Disponível em: <http://www.sepm. gov.br/noticias/documentos-1/Representacao\%20ao\%20CONAR.pdf>. Acesso em: 18 jan. 2012.

QUÉRÉ, Louis. Entre o facto e o sentido: a dualidade do acontecimento. In: Trajectos, Revista de Comunicação, Cultura e Educação, n. 6, 2005, p. 59-75.

ROMAN, Clara. Mais uma da Amélia Bündchen. In: Carta Capital, São Paulo, 27 set. 2011. Disponível em: <http://www.cartacapital.com.br/sociedade/gisele-bundchen-e-o-sexismo/>. Acesso em: 19 set. 2012. 
SEABRA, Luciana. Governo quer suspensão de propaganda da Hope com Gisele. In: O Globo, Rio de Janeiro, 29 set. 2011. Disponível em: <http://oglobo.globo.com/economia/governo-quer-suspensaode-propaganda-da-hope-com-gisele-2746086\#ixzz1|2buXZxU>. Acesso em: 19 set. 2012.

TAMZALI, Wassyla. Une femme en colère: Lettre d'Alger aux Européens désabusés. Paris: Editions Gallimard, 2009.

VARGAS, André. Gisele Bündchen de lingerie é alvo do moralismo oficial. In: Veja, São Paulo, 1o out. 2011. Disponível em: <http://veja.abril.com.br/noticia/brasil/gisele-bundchen-de-lingerie-e-alvodo-moralismo-oficial>. Acesso em: 19 set. 2012.

WOOLF, Virginia. Um teto todo seu. Rio de Janeiro: Nova Fronteira, 1985.

Artigo recebido em agosto de 2011

e aprovado em março de 2012. 